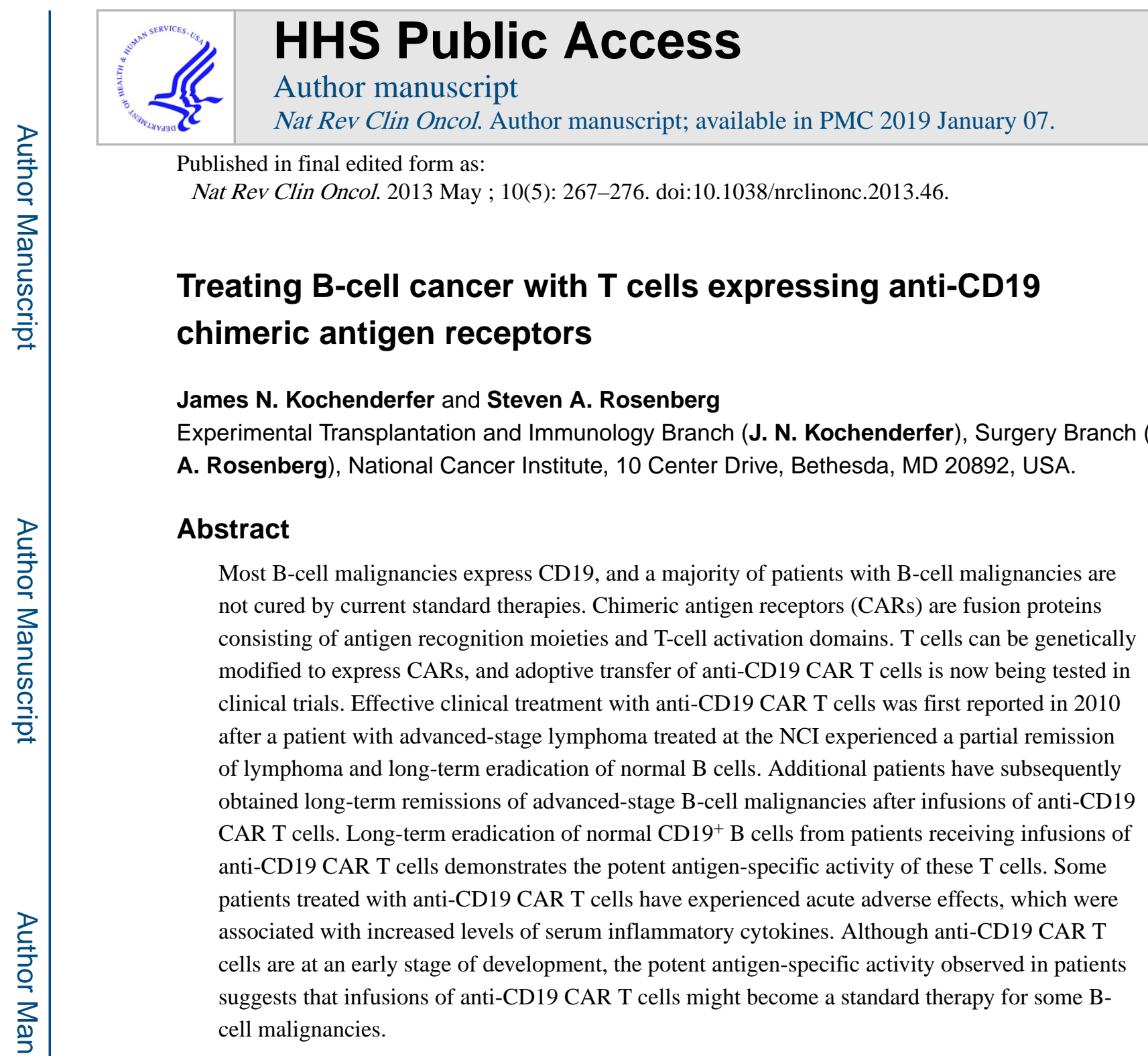

\title{
Introduction
}

Approximately 84,000 people were diagnosed with B-cell malignancies in the USA in 2012. ${ }^{1,2}$ B-cell malignancies comprise a heterogeneous group of leukaemias and lymphomas and, despite substantial recent progress in the treatment of B-cell malignancies, many patients succumb to these diseases. Approximately $30-50 \%$ of newly diagnosed patients with the most-common lymphoma, diffuse large B-cell lymphoma (DLBCL), are not cured by standard first-line treatment regimens of chemotherapy plus monoclonal antibodies. ${ }^{3-6}$ Except for a small subset of patients who undergo allogeneic haematopoietic stem-cell transplantation (alloHSCT), adult patients with most B-cell malignancies—including

Correspondence to: J. N. Kochenderfer, kochendj@mail.nih.gov.

Author contributions

Both authors researched data for the article and made a substantial contribution to the discussion of the content. J. N. Kochenderfer wrote the article, and both authors revised and edited it before submission.

Competing interests

S. A. Rosenberg declares an association with the following company: Kite Pharma. See the article online for full details of the relationship. J. N. Kochenderfer declares no competing interests. 
chronic lymphocytic leukaemia (CLL) and mantle-cell lymphoma—cannot generally be cured by current approaches; $;{ }^{7,8}$ new therapies for these diseases are clearly needed.

Immunotherapies such as the anti-CD20 monoclonal antibody rituximab and the bispecific antibody blina-tumomab can be useful treatments for B-cell malignancies. ${ }^{9,10}$ For example, adding rituximab to chemotherapy regimens improved overall survival of patients with Bcell malignancies; ${ }^{3,8,9,11}$ however, rituximab administered as a single agent is not curative. 7,8,11 By contrast, alloHSCT can cure a variety of B-cell malignancies. ${ }^{12-15}$

Nonmyeloablative alloHSCT regimens include doses of chemotherapy and radiotherapy that are much lower than the chemotherapy and radiotherapy doses used in traditional myeloablative transplant regimens; patients receiving nonmyeloablative transplant regimens would spontaneously recover haematopoiesis without an infusion of allogeneic stem cells, whereas patients receiving myeloablative regimens would probably suffer permanent bone marrow aplasia without an infusion of donor stem cells. ${ }^{14-17}$ Nonmyeloablative alloHSCT depends on cellular immune responses against allogeneic antigens to eradicate malignancy; 16,17 however, these immune responses can also target nonmalignant tissues and cause the potentially fatal complication of graft-versus-host disease (GVHD). ${ }^{17-19}$ Nonrelapse mortality after alloHSCT is defined as death that occurs in patients who have not had progression of their primary malignancy. ${ }^{15}$ GVHD is a main cause of nonrelapse mortality occurring after nonmyeloablative alloHSCT, and nonrelapse mortality rates 3 years after nonablative alloHSCT generally range from $15 \%$ to $40 \% .{ }^{13-19}$ Results of treatment with monoclonal antibodies and nonmyeloablative alloHSCT demonstrate that immunotherapy can be effective in patients with B-cell malignancies, but much room for improvement remains. The development of new immunotherapies with greater efficacy than monoclonal antibodies and less toxicity than alloHSCT would be a major advance in the treatment of Bcell malignancies.

\section{Chimeric antigen receptors}

One potential way to improve immunotherapy of B-cell malignancies is to develop approaches using $\mathrm{T}$ cells targeted specifically to antigens expressed by B-cell malignancies. Tumour-infiltrating lymphocytes (TILs) can be cultured from resected melanoma tumours and returned to the patient in an approach called adoptive T-cell therapy. ${ }^{20-23}$ This approach has been shown to mediate durable, complete regressions of metastatic melanoma. ${ }^{20-23} \mathrm{~T}$ cells can also be prepared for adoptive transfer by genetically modifying the $\mathrm{T}$ cells to express receptors that specifically recognize tumour-associated antigens. ${ }^{21,23-29}$ Genetic modification of $\mathrm{T}$ cells is a quick and reliable process, and clinical trials of genetically modified $\mathrm{T}$ cells targeting a variety of malignancies have been carried out. ${ }^{21,30-33}$

Genetically modified antigen-specific $\mathrm{T}$ cells can be generated from peripheral blood mononuclear cells in sufficient numbers for clinical treatment within 10 days. ${ }^{31}$ There are two approaches for generating antigen-specific $\mathrm{T}$ cells by genetic modification: introducing genes encoding natural $\alpha \beta$ T-cell receptors (TCRs) or introducing genes encoding chimeric antigen receptors (CARs). ${ }^{21,23,25,28}$ CARs are fusion proteins incorporating antigen recognition moieties and T-cell activation domains (Figure 1). ${ }^{27,34-36}$ The antigen-binding domains of most CARs currently undergoing clinical and preclinical development are 
antibody variable regions..$^{25,27,34,36}$ TCRs recognize peptides presented by human leukocyte antigen (HLA) molecules; therefore, TCRs are HLA-restricted, and a particular TCR will only be useful in patients expressing certain HLA molecules. ${ }^{21,23,25,34}$ This specificity limits the number of patients who could be treated with $\mathrm{T}$ cells genetically modified to express a TCR. By contrast, CARs recognize intact cell-surface proteins and glycolipids, so CARs are not HLA-restricted and can be used to treat patients regardless of their HLA types. ${ }^{21,25,37-39}$

Preclinical experiments evaluating CAR-expressing T cells as cancer therapy were initiated in 1993. ${ }^{40,41}$ These experiments led to a clinical trial of CAR-transduced T cells targeting the $a$-folate receptor on ovarian cancer cells; no tumour regressions were observed during this clinical trial. ${ }^{42}$ CARs that are capable of recognizing a variety of tumour-associated antigens have been evaluated in many centres. ${ }^{25,34}$ Preclinical studies have assessed a variety of factors that could affect the in vivo function of CAR-expressing T cells. Multiple approaches for inserting CAR genes into T cells by using gammaretroviruses, ${ }^{30,33,43-48}$ lentiviruses, ${ }^{31,49-52}$ or transposon systems, ${ }^{53,54}$ have been assessed. Furthermore, because all methods of T-cell genetic modification require a period of in vitro culture, various T-cell culture techniques have been evaluated for producing genetically modified T cells. ${ }^{31,43,55}$ Different portions of CARs (Figure 1) including antigen-recognition moieties, extracellular structural components, co-stimulatory domains (such as the cytoplasmic portion of the $\mathrm{CD} 28$ protein), and T-cell-activation moieties (such as the signalling domains of the $\mathrm{CD} 3 \zeta$ protein) can all be important to the in vivo function of CAR-expressing T cells, and all of these portions of CARs remain the subject of intensive investigation. ${ }^{34,43,50,56-59}$ Much of the preclinical work evaluating CARs has been performed with CARs that target the B-cell antigen CD19. $43,45,47,53,60-62$

\section{Preclinical anti-CD19 CAR development}

CD19 is an appealing target for immunotherapy because it is uniformly expressed by the vast majority of B-cell malignancies. ${ }^{63}$ Importantly, expression of CD19 in normal tissues is restricted to mature B cells, B-cell precursors, and many plasma cells; CD19 might also be expressed by follicular dendritic cells. ${ }^{63-65}$ Early experiments demonstrated that anti-CD19 CARs could activate T cells in a CD19specific manner. ${ }^{47,53}$ The anti-CD19 CARs used in these studies contained antigen-binding regions derived from anti-CD19 monoclonal antibodies and T-cell activation domains from the $\mathrm{CD} 3 \zeta$ protein. ${ }^{47,53} \mathrm{~T}$ cells genetically modified to express these CARs could kill CD19 ${ }^{+}$primary leukaemia cells in vitro ${ }^{47,53}$ and eliminate $\mathrm{CD} 19^{+}$target cells in murine xenograft models. ${ }^{47}$

Data suggesting that T-cell co-stimulation had an important role in the activity of CARexpressing $\mathrm{T}$ cells in vivo led investigators to add signalling moieties from the costimulatory molecule CD28 to CARs. ${ }^{47,57}$ These studies showed that adding CD28 moieties to CARs enhanced antigen-specific cytokine production and proliferation by anti-CD19 CAR T cells. ${ }^{57,66,67} \mathrm{~T}$ cells expressing CARs with CD28 signalling moieties and CD3C signalling domains were more effective at eradicating human leukaemia cells from mice than T cells expressing CARs without CD28 moieties. ${ }^{66,67}$ Subsequently, CARs incorporating other signalling domains from co-stimulatory molecules, such as TNF receptor superfamily member 9 (4-1BB, also known as CD137), were developed. ${ }^{49}$ Anti-CD19 
CARs containing the signalling domains of both $4-1 \mathrm{BB}$ and $\mathrm{CD} 3 \zeta$ were superior at eradicating human malignant cells from mice than CARs containing the signalling domains of CD3 $\zeta$ without any co-stimulatory domains. ${ }^{50,56}$ Similar to CD28, including 4-1BB signalling moieties in CARs led to increased CD19-specific proliferation and enhanced in vivo persistence. ${ }^{50}$ In contrast to $\mathrm{T}$ cells expressing a CAR with a CD28 moiety, the increased in vitro proliferation and prolonged in vivo persistence of $\mathrm{T}$ cells expressing a 4 1BB-containing CAR occurred whether or not the $\mathrm{T}$ cells were exposed to the antigen that the CAR recognized. ${ }^{50,56}$ Antigen-independent proliferation of 4-1BB-containing CARs could be a positive characteristic that could enhance the anticancer efficacy of the CARexpressing T cells, but antigen-independent proliferation could increase cell-mediated acute toxicity, and it raises the issue of immortalization of the infused T cells. Immortalization of $\mathrm{T}$ cells transduced with the gene for interleukin (IL)- 15 has been previously reported, ${ }^{68}$ and all efforts to increase T-cell persistence should be balanced with the critical need to avoid malignant transformation.

Other approaches to increase the persistence and proliferation of anti-CD19 CAR T cells have been evaluated. Adoptive T-cell therapies for treating malignancies expressing EpsteinBar virus (EBV) antigens have been developed. ${ }^{69-71} \mathrm{In}$ an attempt to improve the persistence of CAR-expressing T cells, investigators have developed methods to derive antiCD19 CAR T cells that recognize antigens from common viruses such as EBV. ${ }^{60,72,73}$ These $\mathrm{T}$ cells recognize CD19 through their CARs, and they recognize the viral antigens through their natural T-cell receptors. ${ }^{59,72,73}$ Selecting central memory cells for genetic modification, and genetic modification of allogeneic cord blood $\mathrm{T}$ cells are additional strategies entering clinical trials. ${ }^{52,72-74}$

Depleting endogenous lymphocytes by administering chemotherapy or radiotherapy before infusions of tumour-antigen-specific $\mathrm{T}$ cells dramatically enhanced the antitumour efficacy of the transferred $\mathrm{T}$ cells in a variety of murine models. ${ }^{21,23,75-78}$ Depletion of endogenous lymphocytes enhances adoptive T-cell therapy by multiple mechanisms, including depletion of regulatory $\mathrm{T}$ cells and elevation of serum cytokines including IL-15 and IL-7. ${ }^{76,78}$ Experiments in a murine xenograft model showed that regulatory $\mathrm{T}$ cells could impair the antitumour efficacy of anti-CD19 CAR T cells. ${ }^{79}$ Experiments with a syngeneic murine model showed that lymphocyte-depleting total body irradiation administered before infusions of anti-CD19-CAR-transduced $\mathrm{T}$ cells was required for the $\mathrm{T}$ cells to eradicate lymphoma. ${ }^{62}$ In addition, T cells transduced with an anti-CD19 CAR were superior to a monoclonal antibody sharing the CAR's antigen-binding regions at treating lymphoma in lymphocyte-depleted mice. ${ }^{62}$

\section{Clinical results}

Several clinical trials of anti-CD19 CAR T cells have reported results from patients receiving autologous CAR-modified T cells (Table 1). ${ }^{30,31,33,44,48,80,81}$ An important point to remember when interpreting the results of these trials is that the lymphocyte-depleting chemotherapy used in most of the trials could potentially contribute to the reported remissions of B-cell malignancies. The first patients treated with anti-CD19-CAR T cells received $\mathrm{T}$ cells that were genetically modified by plasmid vector electrotransfer. ${ }^{81}$ This 
approach required a long in vitro culture period that lasted 55 days and required in vitro selection to yield high levels of CAR expression. ${ }^{81}$ Evidence of in vivo biological activity of the infused anti-CD19-CAR T cells was not detected in either of the two patients treated with this approach. ${ }^{81}$

The next anti-CD19 CAR clinical trials that were initiated used gammaretroviral transduction as the method of genetic modification. ${ }^{30,33,44,48}$ Genetically modifying T cells with gammaretroviruses consistently causes high and sustained levels of expression of introduced genes without in vitro selection, ${ }^{30,33,44,48}$ and genetic modification of mature $\mathrm{T}$ cells with gammaretroviruses has a long history of safety in humans. ${ }^{46,82}$ The first-in-human evidence of antigen-specific activity of anti-CD19 CAR T cells was generated during a clinical trial in the Surgery Branch of the NCI in a patient who experienced a dramatic regression of advanced follicular lymphoma. ${ }^{44}$ This clinical trial used a gamma retroviral vector to introduce an anti-CD19 CAR containing the signalling domains of the CD28 and CD3 $\zeta$ molecules. ${ }^{44}$ The anti-CD19 CAR-transduced $\mathrm{T}$ cells were prepared by using a $24-$ day in vitro culture process. The clinical treatment regimen consisted of lymphocytedepleting chemotherapy followed by an infusion of anti-CD19 CAR T cells and a course of high-dose IL-2. The first patient treated on this protocol had a large disease burden of follicular lymphoma on recruitment to the trial (patient 1 in Table 2). This first patient experienced no acute adverse effects except for a low-grade fever that lasted for 2 days, and he obtained a partial remission that lasted for 32 weeks. ${ }^{44}$ Bone marrow biopsies revealed a complete elimination of extensive bone marrow lymphoma that was present before treatment; in addition, normal B-lineage cells were completely eradicated from the bone marrow, and the eradication persisted for over 36 weeks (Figure 2) ${ }^{44} \mathrm{~B}$ cells were also completely absent from the blood during this time, while $\mathrm{T}$ cells and other blood cells recovered rapidly. ${ }^{44}$ Progressive lymphoma was detected in the patient's cervical lymph nodes 7 months after the anti-CD19 CAR T cell infusion. As the lymphoma was still CD19+, patient 1 was treated a second time with anti-CD19 CAR T cells. The first and second treatment regimens were the same except the patient received a higher dose of cells with the second treatment (Table 2). After the second treatment, the patient obtained a second partial remission that lasted for 33 months (Table 2). ${ }^{33}$ Seven more patients were subsequently treated with the same regimen of chemo therapy, anti-CD19 CAR T cells, and high-dose IL-2 (Table 2) ${ }^{33}$ In four of the seven evaluable patients on the trial, administration of antiCD19 CAR T cells was associated with a profound and prolonged B-cell depletion, which lasted for over 36 weeks. ${ }^{33,44}$ The B-cell depletion could not be attributed to the chemotherapy that was administered because blood B-cells recovered to normal levels in 819 weeks in patients receiving the same chemotherapy plus infusions of $\mathrm{T}$ cells targeting NY-ESO or gp100, which are antigens that are not expressed by B cells. ${ }^{44}$ Because normal B cells express CD19, prolonged normal B-cell depletion after anti-CD19 CAR T-cell infusions demonstrated that $\mathrm{CAR}$-expressing $\mathrm{T}$ cells had a powerful ability to eradicate $\mathrm{CD} 19^{+}$cells in humans. All of the patients with long-term B-cell depletion obtained either complete or partial remissions of their malignancies, and the four patients with long-term Bcell depletion also developed hypogammaglobulinemia. Hypogammaglobulinemia in these patients was routinely treated with infusions of intravenous immunoglobulins. Six of the seven evaluable patients had remissions of their malignancies (Table 2), two of which were 
complete remissions of CLL. ${ }^{33}$ Both of these complete remissions were confirmed by multicolour flow cytometry of bone-marrow cells (Figure 3). ${ }^{33}$ One of these complete remissions lasted 24 months, and the other is ongoing at 21 months (Table 2 and Figure 4). ${ }^{33}$ Most patients treated with this regimen of chemotherapy, anti-CD19 CAR T cells, and IL-2 experienced significant acute adverse effects including fever, hypotension, and fatigue. ${ }^{33}$ All of these adverse effects peaked within 10 days after the cell infusion and resolved less than 3 weeks after the cell infusion. ${ }^{33}$ These acute adverse effects correlated with serum levels of the inflammatory cytokines TNF and interferon (IFN)- $\gamma$, and T cells producing these inflammatory cytokines in a CD19-specific manner were detected in the blood of patients after the anti-CD19 CAR T cell infusions. ${ }^{33}$

In response to the adverse effects experienced by the patients in the first-in-man study, multiple changes were made to the clinical protocol and the anti-CD19 CAR T-cell production process. The dose of cells administered was decreased, and administration of IL-2 was eliminated. The current adult autologous anti-CD19 CAR protocol used in the Surgery Branch of the NCI consists of cyclophosphamide and fludarabine chemotherapy followed by a single infusion of $2.5 \times 10^{6} \mathrm{CAR}^{+} \mathrm{T}$ cells per $\mathrm{kg}$ of recipient body weight (Figure 5). In addition, the cell culture method used to produce the anti-CD19 CAR T cells was shortened from 24 days to 10 days. Infusing cells that are cultured for a shorter period of time simplifies preparation of the clinical cell product; furthermore, a shorter culture period might improve the ability of the adoptively transferred $\mathrm{T}$ cells to eradicate malignancy as has been shown in murine models. ${ }^{21,83}$ To date, six patients have been treated with this modified approach and although results for most patients are immature, all four evaluable patients have obtained remissions of their malignancies, and high levels of $\mathrm{CAR}^{+}$ cells have been detected in the blood of all patients with sufficiently long follow-up to allow assessment of persistence of the infused cells.

In a clinical trial conducted at the Memorial Sloan-Kettering Cancer Center, nine patients, including eight patients with CLL and one patient with acute lymphocytic leukaemia (ALL), were treated with a protocol that used a gammaretroviral vector to modify $\mathrm{T}$ cells with an anti-CD19 CAR containing CD28 and CD3C domains. ${ }^{30}$ The first three patients treated on this trial received an infusion of anti-CD19 CAR T cells alone, and the remaining six patients received cyclophosphamide chemotherapy before the anti-CD19 CAR T-cell infusion. ${ }^{30}$ No regressions of CLL or depletion of normal B cells were observed in the three patients treated without the cyclophosphamide-conditioning regimen. ${ }^{30}$ A delayed regression of adenopathy occurred between 4 weeks and 14 weeks after anti-CD19 CAR Tcell infusion in one of the four evaluable patients with CLL receiving cyclophosphamide followed by a CAR-transduced T-cell infusion. ${ }^{30}$ One patient on this trial died with hypo tension, renal failure, and elevated serum levels of inflammatory cytokines. ${ }^{84}$ This outcome was thought to be due to an undiagnosed infection that was present before the antiCD19 CAR T-cell infusion, because elevated levels of serum inflammatory cytokines were detectable before the CAR-transduced T-cell infusion. ${ }^{84}$ Other patients who took part in this clinical trial experienced milder adverse effects that were probably associated with the antiCD19 CAR T cells, such as fever and hypotension. ${ }^{30}$ 
The CARs used in the clinical trials conducted at the NCI and at Memorial Sloan-Kettering Cancer Center have a similar structure and design. ${ }^{30,33}$ Despite the similar design of these CARs, substantial differences existed between the T cells infused on the two trials. ${ }^{30,33}$ For example, $\mathrm{CD}^{+}{ }^{+} \mathrm{T}$ cells made up a mean of $46 \%$ of the infused cells in the trial reported by Kochenderfer et al.. ${ }^{33}$ and $\mathrm{CD} 4^{+} \mathrm{T}$ cells made up a mean of $83 \%$ of the infused T cells in the trial of Brentjens et al. ${ }^{30}$ In addition, all of the anti-CD19 CAR T-cell products infused in the trial reported by Kochenderfer et al. ${ }^{33}$ produced substantial amounts of IL-2 in a CD19specific manner at the time of infusion, but the T cells infused to most of the patients in the trial of Brentjens et al. ${ }^{30}$ produced minimal amounts of IL-2. Although the reasons for the differences in the infused $\mathrm{T}$ cells are unclear, the different cell-culture approaches used in the two trials might have contributed to the differences in the $\mathrm{T}$ cells infused in these trials. The clinical importance of these biological differences remains to be determined.

The effect of adding the signalling domain of CD28 to CARs was tested in a study in which patients at the Baylor College of Medicine received simultaneous infusions of two populations of T cells. ${ }^{48}$ One population of T cells was transduced with an anti-CD19 CAR containing signalling domains from $\mathrm{CD} 3$ and $\mathrm{CD} 28$, and the other population was transduced with a CAR that was identical except that it lacked the CD28 domain. ${ }^{48} \mathrm{By}$ simultaneously infusing both T-cell populations into the patients, the persistence of the Tcell populations could be compared using PCR assays that could distinguish the nucleotide sequence of the CD28-containing CAR and the sequence of the CAR lacking CD28. ${ }^{48}$ Compared to T cells transduced with CARs lacking a CD28 domain, CARs with a CD28 domain had higher peak blood levels and enhanced persistence. ${ }^{48}$ This trial did not include chemotherapy before the T-cell infusion, and no remissions of malignancy occurred in the six patients who were treated; in addition patients did not suffer significant to xicities attributable to the anti-CD19 CAR T cells. ${ }^{48}$

Investigators from the University of Pennsylvania reported results from three patients who received infusions of $\mathrm{T}$ cells modified with a lentiviral vector to express an anti-CD19 CAR containing the signalling domain of the 4-1BB molecule along with the signalling domain of the $\mathrm{CD} 3 \zeta$ molecule. ${ }^{31,51}$ The three reported patients on this trial each received a different chemotherapy regimen within a few days before their CAR-transduced T-cell infusions: ${ }^{31,51}$ one patient received bendamustine, one patient received bendamustine plus rituximab, and the third patient received pentostatin plus cyclophosphamide. ${ }^{31}$ This was the first clinical trial to test a CAR containing a 4-1BB moiety. ${ }^{31,51}$ Two of the three patients obtained prolonged complete remissions of CLL after infusion of the anti-CD19 CAR T cells. ${ }^{31,51}$ The $\mathrm{CAR}^{+} \mathrm{T}$ cells infused into the patients on this trial underwent in vivo proliferation and levels persisted in the blood for several months. CAR-expressing memory $\mathrm{T}$ cells were detected, and persisting T cells that could be activated by ex vivo exposure to CD19 were demonstrated. ${ }^{31}$ One of the patients developed tumour lysis syndrome that was treated successfully with rasburicase. ${ }^{51}$ Other reported adverse effects in this trial included fevers and mild hypotension. ${ }^{31,51}$ Interestingly, the adverse effects reported from this trial were sometimes delayed. In the patient with tumour lysis syndrome, the diagnosis of this condition was not made until 22 days after the cell infusion. ${ }^{51}$ Normal B cells were eliminated from patients on this trial, and two of the three patients experienced hypogammaglobulinemia. ${ }^{31,51}$ 
Several additional groups have initiated clinical trials of anti-CD19 CAR T cells. 30,31,33,44,48,51,81 Currently, 18 clinical trials of adoptive T-cell therapy with anti-CD19

CAR-expressing T cells are actively recruiting patients (Table 3 ). Some of these trials are recruiting patients who have never undergone HSCT, and some trials are recruiting patients with persistent or relapsed malignancy after alloHSCT (Table 3). Most trials use autologous mature $\mathrm{T}$ cells, but some trials use allogeneic mature $\mathrm{T}$ cells or cord blood $\mathrm{T}$ cells (Table 3 ).

\section{Factors affecting efficacy and toxicity}

Despite the limited number of patients treated with anti-CD19 CAR T cells, preclinical experiments combined with early clinical results allow us to identify some factors that probably have a major impact on the in vivo activity of anti-CD19 CAR T cells. The particular co-stimulator y domains and T-cell activation domains included in CARs affect the in vitro and the in vivo function of CAR-expressing T cells. ${ }^{48,50,57,66,67}$ Differences in other parts of the CAR, including the structural components that connect the antigenrecognition moiety to the co-stimulatory and T-cell activation domains can potentially affect the biological activity of CAR-expressing T cells. ${ }^{59}$ Multiple reports demonstrate an advantage associated with the inclusion of either CD28 signalling domains or 4-1BB signalling domains in CARs, ${ }^{48,50,66,67}$ but the optimal sequences to include in each part of antiCD19 CARs have not been determined, and optimizing these sequences is a subject of ongoing research. In addition, the type of gene-transfer vector used to genetically modify $\mathrm{T}$ cells could affect in vivo function, and different groups are investigating gammaretroviral vectors, lentiviral vectors, and transposon-based vectors. . $^{30,31,33,52,54}$

The cell culture and genetic modification methods used to produce anti-CD19 CAR T cells for clinical use vary among the different reported clinical trials. ${ }^{30,31,33,48,81}$ These differences in T-cell production methods could impact the in vivo function of anti-CD19 CAR T cells. Animal models indicate that shorter periods of in vitro culture yield cells with a less-differentiated phenotype that is associated with better in vivo anticancer activity. ${ }^{21,83}$ As with other factors that might affect the efficacy of antiCD19 CAR T cells, the optimal method of cell production has not been determined.

As mentioned previously, eradication of malignancy in murine models is dramatically enhanced when either chemotherapy or radiation is administered to deplete endogenous lymphocytes before adoptive T-cell transfer. ${ }^{61,77,78}$ The degree of lymphocyte depletion that can optimally enhance anti-CD19 CAR T-cell efficacy without causing excessive toxicity is not known. The optimal radiotherapy or chemotherapy regimen to administer before infusions of anti-CD19 CAR T cells also has not been determined.

One of the biggest challenges facing the field of anti-CD19 CARs is acute adverse effects that follow infusions of the CAR-expressing T cells. ${ }^{30,31,33,51}$ Reported adverse effects include fevers, hypotension, and extreme fatigue. ${ }^{30,31,33,51}$ Acute adverse effects after antiCD19 CAR T-cell infusions have been shown to correlate with serum levels of the inflammatory cytokines IFN $\gamma$ and TNF. ${ }^{33}$ An important goal of the field is to decrease toxicity while maintaining or enhancing the antimalignancy activity of the CAR-expressing $\mathrm{T}$ cells. Possible approaches to achieve this goal include designing CARs that produce lower 
levels of inflammatory cytokines upon antigen-specific stimulation, adjusting cell culture methods to produce $\mathrm{T}$ cells that make lower levels of inflammatory cytokines, and administering drugs to block inflammatory cytokines such as TNF or IL-1. ${ }^{85,86}$ Another approach for controlling toxicity is to include suicide genes in CARs, so infused $\mathrm{T}$ cells could be rapidly eliminated if severe toxicity occurs. ${ }^{87,88}$

Endogenous normal B cells and malignant B cells might stimulate anti-CD19-CARexpressing $\mathrm{T}$ cells to proliferate and to produce cytokines. On the one hand, stimulation of proliferation by large numbers of endogenous $\mathrm{CD} 19^{+}$cells might enhance persistence and anti-malignancy activity of the anti-CD19 CAR T cells. On the other hand, murine experiments showed an enhancement of lymphoma treatment when $\mathrm{CD} 20^{+}$normal B cells were depleted by treating mice with a mono clonal antibody before infusion of anti-CD20 CAR T cells. ${ }^{89}$ Nonmalignant and malignant CD19+ B cells likely stimulate inflammatory cytokine production by anti-CD19 CAR T cells in vivo, which probably increases toxicity because levels of serum inflammatory cytokines following anti-CD19 CAR T-cell infusions was shown to correlate with toxicity. ${ }^{33}$ One possible strategy to decrease toxicity associated with anti-CD19 CAR T cell therapy is to reduce the number of endogenous normal B cells and malignant $\mathrm{B}$ cells in patients. This reduction could be accomplished by administering chemotherapy or monoclonal antibodies before the anti-CD19 CAR T-cell infusions.

\section{Conclusions}

New curative treatments are needed for B-cell malignancies. Many patients have already obtained complete remissions from advanced-stage B-cell malignancies during phase I clinical trials of anti-CD19 CAR T cells. Several of these complete remissions have been long-lasting and were associated with an absence of minimal residual malignancy. ${ }^{31,33,51}$ Infusions of autologous anti-CD19 CAR T cells can completely eradicate blood and bone marrow B cells for prolonged periods of time. This B-cell eradication demonstrates the powerful biological activity of anti-CD19 CAR T cells. ${ }^{31,33,44,51}$ Results so far provide encouragement that infusions of autologous anti-CD19-CAR T cells can be developed into an immunotherapy with greater efficacy than monoclonal antibodies, but less toxicity than alloHSCT. The field of CARs is young, and much improvement remains to be made, but infusions of anti-CD19 CAR T cells hold great promise to become an important standard therapy for B-cell malignancies in the near future.

\section{Acknowledgements}

This work was supported by intramural funding of the Center for Cancer Research, National Cancer Institute, NIH, USA.

\section{References}

1. National Cancer Institute. Surveillance Epidemiology and End Results [online], http:// seer.cancer.gov/ (2013).

2. Flowers CR \& Armitage JO A decade of progress in lymphoma: Advances and continuing challenges. Clin. Lymphoma Myeloma Leuk 10, 414-423 (2010). [PubMed: 21156459]

3. Sinha R, DeJoubner N \& Flowers C Novel agents for diffuse large B-cell lymphoma. Expert Opin. Investig. Drugs 20, 669-680 (2011). 
4. Sehn LH et al. The revised International Prognostic Index (R-IPI) is a better predictor of outcome than the standard IPI for patients with diffuse large B-cell lymphoma treated with R-CHOP. Blood 109, 1857-1861 (2007). [PubMed: 17105812]

5. Kenkre VP \& Smith SM Management of relapsed diffuse large B-cell lymphoma. Curr. Oncol. Rep 10, 393-403 (2008). [PubMed: 18706267]

6. Gisselbrecht $\mathrm{C}$ et al. Salvage regimens with autologous transplantation for relapsed large B-cell lymphoma in the rituximab era. J. Clin. Oncol 28, 4184-4190 (2010). [PubMed: 20660832]

7. Cortelazzo S, Ponzoni M, Ferreri AJM \& Dreyling M Mantle cell lymphoma. Crit. Rev. Oncol. Hematol 82, 78-101 (2012). [PubMed: 21658968]

8. Gribben JG \& O'Brien S Update on therapy of chronic lymphocytic leukemia. J. Clin. Oncol 29, 544-550 (2011). [PubMed: 21220603]

9. Feugier $\mathrm{P}$ et al. Long-term results of the R-CHOP study in the treatment of elderly patients with diffuse large B-cell lymphoma: A study by the Groupe d'Etude des Lymphomes de l'Adulte. J. Clin. Oncol 23, 4117-4126 (2005). [PubMed: 15867204]

10. Topp MS et al. Long-term follow-up of hematologic relapse-free survival in a phase 2 study of blinatumomab in patients with MRD in B-lineage ALL. Blood 120, 5185-5187 (2012). [PubMed: 23024237]

11. Van Oers MH \& Kersten MJ Treatment strategies in advanced stage follicular lymphoma. Best Pract. Res. Clin. Haematol 24, 187-201 (2011). [PubMed: 21658618]

12. Dreger $P$ et al. Indications for allogeneic stem cell transplantation in chronic lymphocytic leukemia: The EBMT transplant consensus. Leukemia 21, 12-17 (2007). [PubMed: 17109028]

13. van Besien K Stem cell transplantation for indolent lymphoma. A reappraisal. Blood Rev. 25, 223 228 (2011). [PubMed: 21641099]

14. Khouri IF et al. Nonmyeloablative allogeneic transplantation with or without 90 yttrium ibritumomab tiuxetan is potentially curative for relapsed follicular lymphoma: 12-year results. Blood 119, 6373-6378 (2012). [PubMed: 22586182]

15. Bacher U, Klyuchnikov E, Le-Rademacher J, Carreras J \& Armand P Conditioning regimens for allotransplants for diffuse large B-cell lymphoma myeloablative or reduced intensity? Blood 120, 4256-4262 (2012). [PubMed: 23007405]

16. Sorror ML et al. Long-term outcomes among older patients following nonmyeloablative conditioning and allogeneic hematopoietic cell transplantation for advanced hematologic malignancies. JAMA 306, 1874-1883 (2011). [PubMed: 22045765]

17. Corradini P \& Farina L Allogeneic transplantation for lymphoma: Long-term outcome. Curr. Opin. Hematol 17, 522-530 (2010). [PubMed: 20717024]

18. Hale GA et al. Alternate donor hematopoietic cell transplantation (HCT) in non-Hodgkin lymphoma using lower intensity conditioning: a report from the CIBMTR. Biol. Blood Marrow Transplant 18, 1036-1043.e1 (2012). [PubMed: 22155506]

19. Van Besien K Current status of allogeneic transplantation for aggressive non-Hodgkin lymphoma. Curr. Opin. Oncol 23, 681-691 (2011). [PubMed: 21946246]

20. Rosenberg SA et al. Durable complete responses in heavily pretreated patients with metastatic melanoma using T-cell transfer immunotherapy. Clin. Cancer Res 17, 4550-4557 (2011). [PubMed: 21498393]

21. Restifo NP, Dudley ME \& Rosenberg SA Adoptive immunotherapy for cancer: Harnessing the T cell response. Nat. Rev. Immunol 12, 269-281 (2012). [PubMed: 22437939]

22. Dudley ME et al. Adoptive cell therapy for patients with metastatic melanoma: evaluation of intensive myeloablative chemoradiation preparative regimens. J. Clin. Oncol 26, 5233-5239 (2008). [PubMed: 18809613]

23. Rosenberg SA Cell transfer immunotherapy for metastatic solid cancer-what clinicians need to know. Nat. Rev. Clin. Oncol 8, 577-585 (2011). [PubMed: 21808266]

24. Brenner MK \& Heslop HE Adoptive T cell therapy of cancer. Curr. Opin. Immunol 22, 251-257 (2010). [PubMed: 20171074]

25. Park TS, Rosenberg SA \& Morgan RA Treating cancer with genetically engineered T cells. Trends Biotechnol. 29, 550-557 (2011). [PubMed: 21663987] 
26. Morgan RA et al. Cancer regression in patients after transfer of genetically engineered lymphocytes. Science 314, 126-129 (2006). [PubMed: 16946036]

27. Kershaw MH, Teng MWL, Smyth MJ \& Darcy PK Supernatural T cells: Genetic modification of T cells for cancer therapy. Nat. Rev. Immunol 5, 928-940 (2005). [PubMed: 16322746]

28. Hoyos V, Savoldo B \& Dotti G Genetic modification of human T lymphocytes for the treatment of hematologic malignancies. Haematologica 97, 1622-1631 (2012). [PubMed: 22929977]

29. Turtle CJ, Hudecek M, Jensen MC \& Riddell SR Engineered T cells for anti-cancer therapy. Curr. Opin. Immunol 24, 633-639 (2012). [PubMed: 22818942]

30. Brentjens RJ et al. Safety and persistence of adoptively transferred autologous CD19targeted T cells in patients with relapsed or chemotherapy refractory B-cell leukemias. Blood 118, 48174828 (2011). [PubMed: 21849486]

31. Kalos $\mathrm{M}$ et al. T cells with chimeric antigen receptors have potent antitumor effects and can establish memory in patients with advanced leukemia. Sci. Transl. Med 3, $95 \mathrm{ra} 73$ (2011).

32. Robbins PF et al. Tumor regression in patients with metastatic synovial cell sarcoma and melanoma using genetically engineered lymphocytes reactive with NY-ESO-1. J. Clin. Oncol 29, 917-924 (2011). [PubMed: 21282551]

33. Kochenderfer JN et al. B-cell depletion and remissions of malignancy along with cytokineassociated toxicity in a clinical trial of anti-CD19 chimeric-antigen-receptor-transduced T cells. Blood 119, 2709-2720 (2012). [PubMed: 22160384]

34. Sadelain M, Brentjens R \& Riviere I The promise and pitfalls of chimeric antigen receptors. Curr. Opin. Immunol 21, 215-223 (2009). [PubMed: 19327974]

35. Irving BA \& Weiss A The cytoplasmic domain of the T cell receptor zeta chain is sufficient to couple to receptor-associated signal transduction pathways. Cell 64, 891-901 (1991). [PubMed: 1705867]

36. Eshhar Z, Waks T, Gross G \& Schindler DG Specific activation and targeting of cytotoxic lymphocytes through chimeric single chains consisting of antibody-binding domains and the gamma or zeta subunits of the immunoglobulin and T-cell receptors. Proc. Natl Acad. Sci. USA 90, 720-724 (1993). [PubMed: 8421711]

37. Louis $\mathrm{CU}$ et al. Antitumor activity and longterm fate of chimeric antigen receptor-positive $\mathrm{T}$ cells in patients with neuroblastoma. Blood 118, 6050-6056 (2011). [PubMed: 21984804]

38. Curran KJ, Pegram HJ \& Brentjens RJ Chimeric antigen receptors for T cell immunotherapy: Current understanding and future directions. J. Gene Med 14, 405-415 (2012). [PubMed: 22262649]

39. Pule MA et al. Virus-specific T cells engineered to coexpress tumor-specific receptors: persistence and antitumor activity in individuals with neuroblastoma. Nat. Med 14, 1264-1270 (2008). [PubMed: 18978797]

40. Hwu P et al. Lysis of ovarian cancer cells by human lymphocytes redirected with a chimeric gene composed of an antibody variable region and the Fc receptor gamma chain. J. Exp. Med 178, 361366 (1993). [PubMed: 8315392]

41. Hwu P et al. In vivo antitumor activity of $\mathrm{T}$ cells redirected with chimeric antibody/T-cell receptor genes. Cancer Res. 55, 3369-3373 (1995). [PubMed: 7614473]

42. Kershaw $\mathrm{MH}$ et al. A phase I study on adoptive immunotherapy using gene-modified $\mathrm{T}$ cells for ovarian cancer. Clin. Cancer Res 12, 6106-6115 (2006). [PubMed: 17062687]

43. Kochenderfer JN et al. Construction and preclinical evaluation of an anti-CD19 chimeric antigen receptor. J. Immunother 32, 689-702 (2009). [PubMed: 19561539]

44. Kochenderfer JN et al. Eradication of B-lineage cells and regression of lymphoma in a patient treated with autologous T cells genetically engineered to recognize CD19. Blood 116, 4099-4102 (2010). [PubMed: 20668228]

45. Cheadle EJ, Gilham DE, Thistlethwaite FC, Radford JA \& Hawkins RE Killing of nonHodgkin lymphoma cells by autologous CD19 engineered T cells. Br. J. Haematol 129, 322-332 (2005). [PubMed: 15842655]

46. Scholler J et al. Decade-long safety and function of retroviral-modified chimeric antigen receptor T cells. Sci. Transl. Med 4, 132ra53 (2012). 
47. Brentjens RJ et al. Eradication of systemic B-cell tumors by genetically targeted human T lymphocytes co-stimulated by CD80 and interleukin-15. Nat. Med 9, 279-286 (2003). [PubMed: 12579196]

48. Savoldo B et al. CD28 costimulation improves expansion and persistence of chimeric antigen receptor-modified T cells in lymphoma patients. J. Clin. Invest 121, 1822-1826 (2011). [PubMed: 21540550]

49. Imai $\mathrm{C}$ et al. Chimeric receptors with $4-1 \mathrm{BB}$ signaling capacity provoke potent cytotoxicity against acute lymphoblastic leukemia. Leukemia 18, 676-684 (2004). [PubMed: 14961035]

50. Milone MC et al. Chimeric receptors containing CD137 signal transduction domains mediate enhanced survival of T cells and increased antileukemic efficacy in vivo. Mol. Ther 17, 1453-1464 (2009). [PubMed: 19384291]

51. Porter DL, Levine BL, Kalos M, Bagg A \& June CH Chimeric antigen receptor-modified T cells in chronic lymphoid leukemia. N. Engl. J. Med 365, 725-733 (2011). [PubMed: 21830940]

52. Wang $X$ et al. Phenotypic and functional attributes of lentivirus-modified CD19-specific human $\mathrm{CD}^{+}$central memory T cells manufactured at clinical scale. J. Immunother 35, 689-701 (2012). [PubMed: 23090078]

53. Cooper LJ et al. T-cell clones can be rendered specific for CD19: toward the selective augmentation of the graft-versus-B-lineage leukemia effect. Blood 101, 1637-1644 (2003). [PubMed: 12393484]

54. Kebriaei $\mathrm{P}$ et al. Infusing CD19-directed T cells to augment disease control in patients undergoing autologous hematopoietic stem-cell transplantation for advanced B-lymphoid malignancies. Hum. Gene Ther 23, 444-450 (2012). [PubMed: 22107246]

55. Hollyman D et al. Manufacturing validation of biologically functional T cells targeted to CD19 antigen for autologous adoptive cell therapy. J. Immunother 32, 169-180 (2009). [PubMed: 19238016]

56. Song DG et al. In vivo persistence, tumor localization, and antitumor activity of CARengineered T cells is enhanced by costimulatory signaling through CD137 (4-1BB). Cancer Res. 71, 4617-4627 (2011). [PubMed: 21546571]

57. Maher J, Brentjens RJ, Gunset G, Rivière I \& Sadelain M Human T-lymphocyte cytotoxicity and proliferation directed by a single chimeric TCRS/CD28 receptor. Nat. Biotechnol 20, 70-75 (2002). [PubMed: 11753365]

58. Zhao $\mathrm{Y}$ et al. A herceptin-based chimeric antigen receptor with modified signaling domains leads to enhanced survival of transduced T lymphocytes and antitumor activity. J. Immunol 183, 55635574 (2009). [PubMed: 19843940]

59. Guest RD et al. The role of extracellular spacer regions in the optimal design of chimeric immune receptors: evaluation of four different scFvs and antigens. J. Immunother 28, 203-211 (2005). [PubMed: 15838376]

60. Rossig $\mathrm{C}$ et al. Target antigen expression on a professional antigen-presenting cell induces superior proliferative antitumor T-cell responses via chimeric T-cell receptors. J. Immunother 29, 21-31 (2006). [PubMed: 16365597]

61. Cheadle EJ et al. Natural expression of the CD19 antigen impacts the long-term engraftment but not antitumor activity of CD19-specific engineered T cells. J. Immunol 184, 1885-1896 (2010). [PubMed: 20089697]

62. Kochenderfer JN, Yu Z, Frasheri D, Restifo NP \& Rosenberg SA Adoptive transfer of syngeneic T cells transduced with a chimeric antigen receptor that recognizes murine CD19 can eradicate lymphoma and normal B cells. Blood 116, 3875-3886 (2010). [PubMed: 20631379]

63. Nadler LM et al. B4, a human B lymphocyteassociated antigen expressed on normal, mitogenactivated, and malignant B lymphocytes. J. Immunol 131, 244-250 (1983). [PubMed: 6408173]

64. Uckun FM et al. Detailed studies on expression and function of CD19 surface determinant by using B43 monoclonal antibody and the clinical potential of anti-CD19 immunotoxins. Blood 71, 13-29 (1988). [PubMed: 3257143]

65. Scheuermann RH \& Racila E CD19 antigen in leukemia and lymphoma diagnosis and immunotherapy. Leuk. Lymphoma 18, 385-397 (1995). [PubMed: 8528044] 
66. Brentjens RJ et al. Genetically targeted T cells eradicate systemic acute lymphoblastic leukemia xenografts. Clin. Cancer Res 13, 5426-5435 (2007). [PubMed: 17855649]

67. Kowolik CM et al. CD28 costimulation provided through a CD19-specific chimeric antigen receptor enhances in vivo persistence and antitumor efficacy of adoptively transferred T cells. Cancer Res. 66, 10995-11004 (2006). [PubMed: 17108138]

68. Hsu $\mathrm{C}$ et al. Cytokine-independent growth and clonal expansion of a primary human CD8+ T-cell clone following retroviral transduction with the IL-15 gene. Blood 109, 5168-5177 (2007). [PubMed: 17353346]

69. Bollard CM et al. Complete responses of relapsed lymphoma following genetic modification of tumor-antigen presenting cells and T-lymphocyte transfer. Blood 110, 2838-2845 (2007). [PubMed: 17609424]

70. Bollard CM, Rooney CM \& Heslop HE T-cell therapy in the treatment of post-transplant lymphoproliferative disease. Nat. Rev. Clin. Oncol 9, 510-519 (2012). [PubMed: 22801669]

71. Leen AM et al. Monoculture-derived T lymphocytes specific for multiple viruses expand and produce clinically relevant effects in immunocompromised individuals. Nat. Med 12, 1160-1166 (2006). [PubMed: 16998485]

72. Micklethwaite KP et al. Derivation of human T lymphocytes from cord blood and peripheral blood with antiviral and antileukemic specificity from a single culture as protection against infection and relapse after stem cell transplantation. Blood 115, 2695-2703 (2010). [PubMed: 20110422]

73. Terakura $\mathrm{S}$ et al. Generation of CD19-chimeric antigen receptor modified $\mathrm{CD}^{+} \mathrm{T}$ cells derived from virus-specific central memory T cells. Blood 119, 72-82 (2012). [PubMed: 22031866]

74. Serrano LM et al. Differentiation of naive cordblood T cells into CD19-specific cytolytic effectors for posttransplantation adoptive immunotherapy. Blood 107, 2643-2652 (2006). [PubMed: 16352804]

75. Muranski $\mathrm{P}$ et al. Increased intensity lymphodepletion and adoptive immunotherapy-how far can we go? Nat. Clin. Pract. Oncol 3, 668-681 (2006). [PubMed: 17139318]

76. Klebanoff CA, Khong HT, Antony PA, Palmer DC \& Restifo NP Sinks, suppressors and antigen presenters: How lymphodepletion enhances T cell-mediated tumor immunotherapy. Trends Immunol. 26, 111-117 (2005). [PubMed: 15668127]

77. North RJ Cyclophosphamide-facilitated adoptive immunotherapy of an established tumor depends on elimination of tumor-induced suppressor T cells. J. Exp. Med 155, 1063-1074 (1982). [PubMed: 6460831]

78. Gattinoni L et al. Removal of homeostatic cytokine sinks by lymphodepletion enhances the efficacy of adoptively transferred tumor-specific CD8 ${ }^{+}$T cells. J. Exp. Med 202, 907-912 (2005). [PubMed: 16203864]

79. Lee JC et al. In vivo inhibition of human CD19targeted effector T cells by natural T regulatory cells in a xenotransplant murine model of B cell malignancy. Cancer Res. 71, 2871-2881 (2011). [PubMed: 21487038]

80. Porter CD et al. Comparison of efficiency of infection of human gene therapy target cells via four different retroviral receptors. Hum. Gene Ther 7, 913-919 (1996). [PubMed: 8727505]

81. Jensen MC et al. Antitransgene rejection responses contribute to attenuated persistence of adoptively transferred CD20/CD19-specific chimeric antigen receptor redirected T cells in humans. Biol. Blood Marrow Transplant 16, 1245-1256 (2010). [PubMed: 20304086]

82. Recchia A et al. Retroviral vector integration deregulates gene expression but has no consequence on the biology and function of transplanted T cells. Proc. Natl Acad. Sci. USA 103, 1457-1462 (2006). [PubMed: 16432223]

83. Gattinoni $\mathrm{L}$ et al. Acquisition of full effector function in vitro paradoxically impairs the in vivo antitumor efficacy of adoptively transferred $\mathrm{CD}^{+} \mathrm{T}$ cells. J. Clin. Invest 115, 1616-1626 (2005). [PubMed: 15931392]

84. Brentjens RYR, Bernal Y, Riviere I \& Sadelain M Treatment of chronic lymphocytic leukemia with genetically targeted autologous T cells: a case report of an unforeseen adverse event in a phase I clinical trial. Mol. Ther 18, 666-668 (2010). [PubMed: 20357779]

85. Caorsi R, Federici S \& Gattorno M Biologic drugs in autoinflammatory syndromes. Autoimmun. Rev 12, 81-86 (2012). [PubMed: 22884553] 
86. Yanik GA et al. The impact of soluble tumor necrosis factor receptor etanercept on the treatment of idiopathic pneumonia syndrome after allogeneic hematopoietic stem cell transplantation. Blood 112, 3073-3081 (2008). [PubMed: 18664626]

87. Di Stasi A et al. Inducible apoptosis as a safety switch for adoptive cell therapy. N. Engl. J. Med 365, 1673-1683 (2011). [PubMed: 22047558]

88. Lupo-Stanghellini MT et al. Clinical impact of suicide gene therapy in allogeneic hematopoietic stem cell transplantation. Hum. Gene Ther 21, 241-250 (2010). [PubMed: 20121594]

89. James SE et al. Antibody-mediated B-cell depletion before adoptive immunotherapy with $\mathrm{T}$ cells expressing CD20-specific chimeric T-cell receptors facilitates eradication of leukemia in immunocompetent mice. Blood 114, 5454-5463 (2009). [PubMed: 19880489] 


\section{Key points}

- $\quad$ T cells can be genetically modified to express chimeric antigen receptors (CARs), which are fusion proteins made up of antigen-recognition moieties and T-cell activation domains

- $\quad$ CD19 is a suitable target for CAR T cells because it is expressed by B-cell malignancies, but not by normal essential tissues

- Depleting endogenous lymphocytes by administering chemotherapy or radiotherapy before infusions of adoptively transferred $\mathrm{T}$ cells enhances the in vivo activity of the T cells

- $\quad$ Patients have achieved complete remissions during clinical trials of anti-CD19 CAR T cells; however, acute toxicities associated with elevated serum levels of inflammatory cytokines were noted in trials

- $\quad$ Evidence for biological activity is provided by long-term depletion of CD19+ normal B cells from several patients receiving infusions of anti-CD19 CAR T cells

- $\quad$ Adoptive transfer of anti-CD19 CAR T cells is a potent new form of immunotherapy that has the potential to become an important therapy option for some advanced-stage B-cell malignancies 


\section{Review criteria}

Content to include in this Review was drawn from the authors' experience, reading of the pertinent literature, attendance at major conferences, and personal communication with leaders in the field. 
a
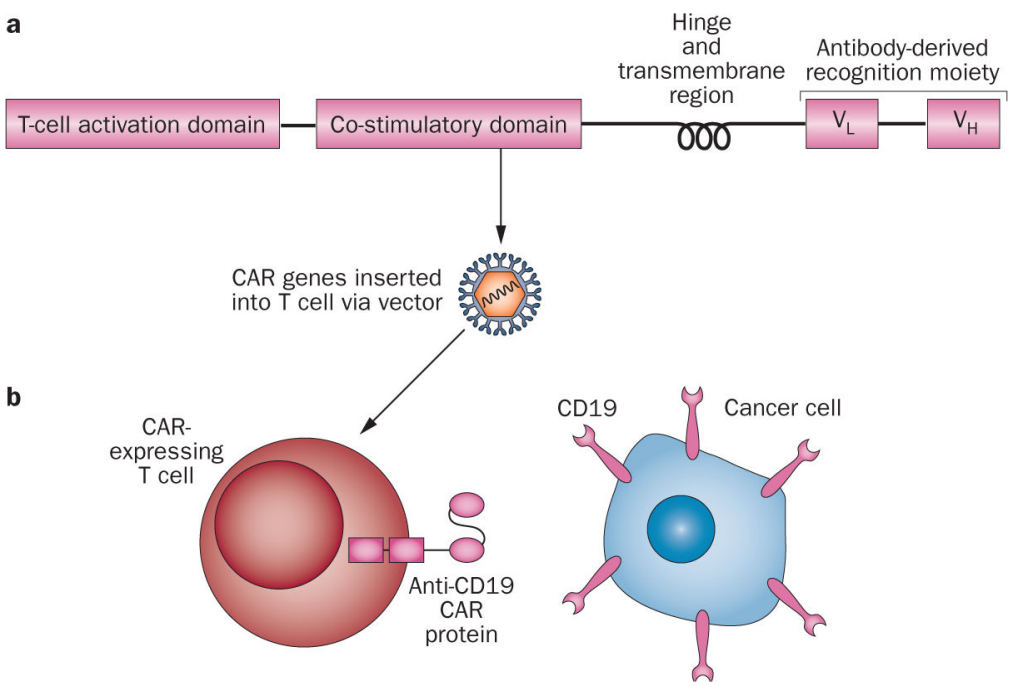

Figure 1 |

Chimeric antigen receptors. a |CARs usually include a T-cell activation domain, one or more co-stimulatory domains, a hinge region, a cell membranespanning transmembrane domain, and an antigen-recognition moiety that is usually derived from an antibody. $\mathbf{b} \mid \mathrm{A}$ schematic of an anti-CD19 CAR-expressing T cell recognizing a CD19+ malignant cell is shown. Abbreviation: $\mathrm{CAR}$, chimeric antigen receptor. 


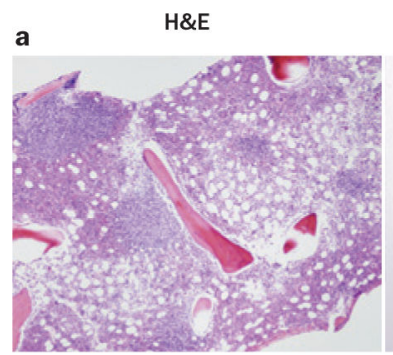

CD19

CD79a

CD20

b
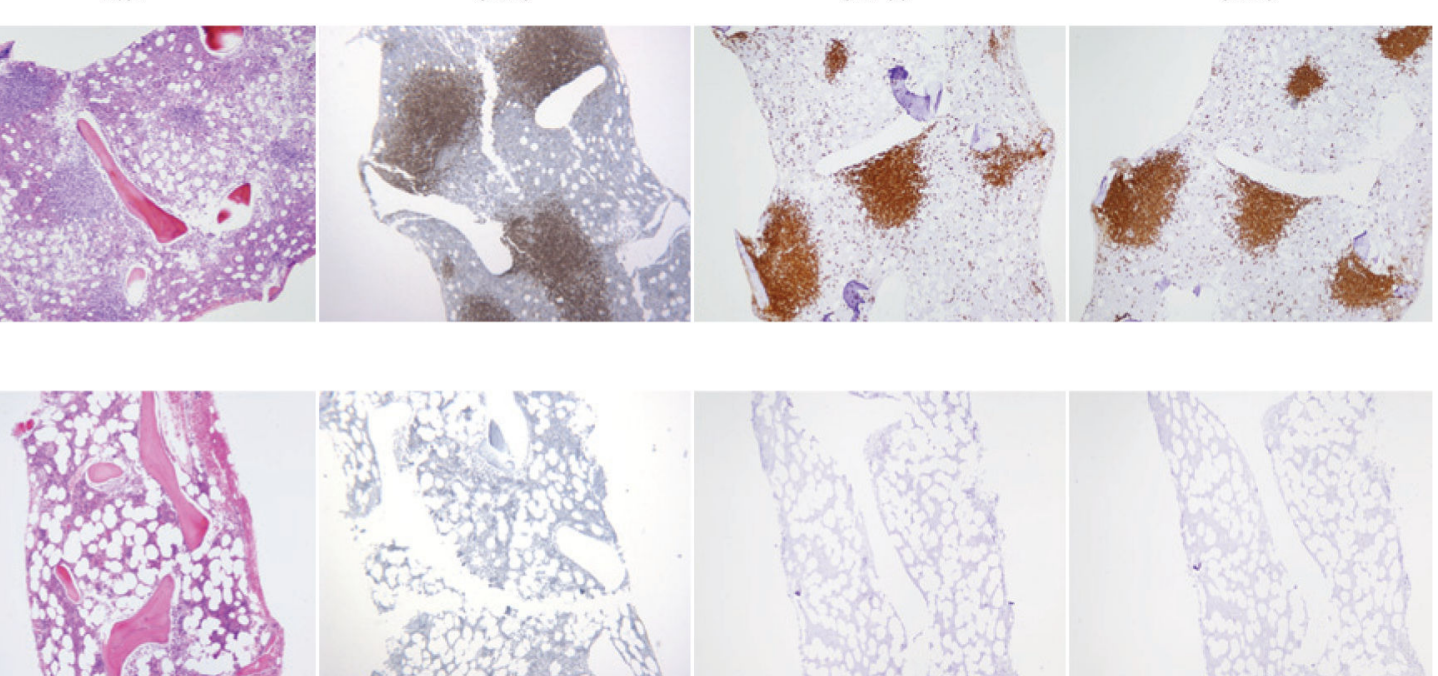

Figure 2 |.

Eradication of bone marrow lymphoma and normal B cells occurred after anti-CD19 CAR T cell infusion. a A patient with follicular lymphoma (patient 1 in Table 1) had extensive bone marrow involvement with lymphoma before treatment with chemotherapy followed by anti-CD19 CAR T cells and IL-2. The lymphoma cells expressed the B-cell markers CD19, CD79a, and CD20. b | 14 weeks after treatment, the lymphoma as well as normal B cells were absent. Abbreviations: CAR, chimeric antigen receptor; H\&E, haematoxylin and eosin; IL, interleukin. The CD19 and CD79a panels of part a are reproduced with permission from American Society of Hematology (C) Kochenderfer, J. N. et al. Blood 116, 4099-4102 (2010). 

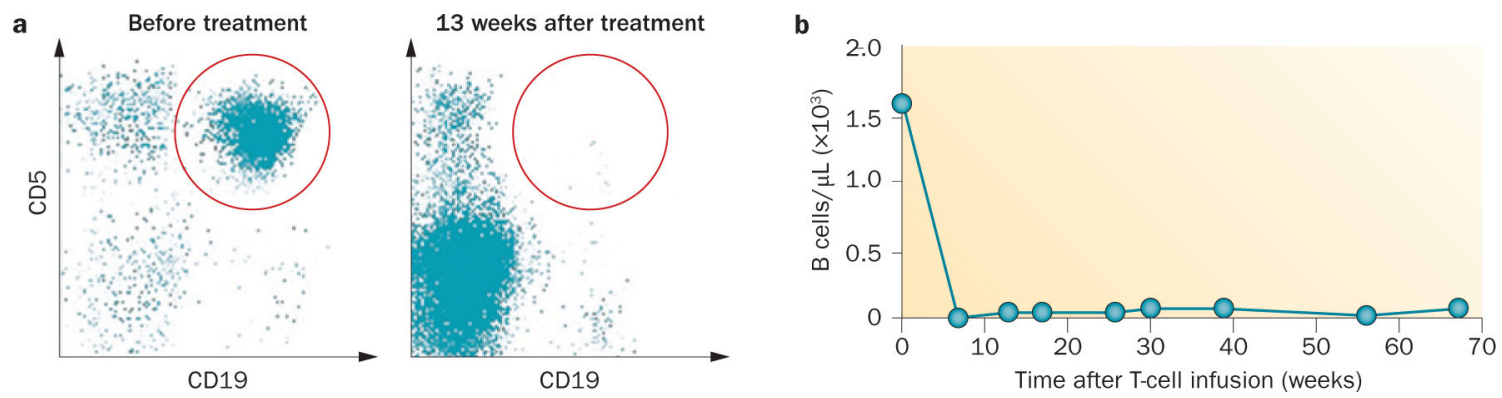

Figure 3 |.

Eradication of bone marrow and blood CLL cells occurred in a patient treated with chemotherapy followed by anti-CD19 CAR T cells and IL-2. a | Before treatment almost all bone marrow CD19+ B-lineage cells also expressed CD5. Expression of CD5 together with CD19 is an aberrant phenotype that is typical for CLL. 14 months after treatment, the aberrant $\mathrm{CD} 19^{+}, \mathrm{CD}^{+}$population is absent. b | Blood B cells, most of which were CLL cells, were eliminated after treatment. B cells, which were defined as CD19+ cells, were assayed by flow cytometry. The results are from patient 3 from Table 1. Abbreviations: CAR, chimeric antigen receptor; CLL, chronic lymphocytic leukaemia; IL, interleukin. Reproduced with permission from American Society of Hematology (C) Kochenderfer, J. N. et al. Blood 119, 2709-2720 (2012). 

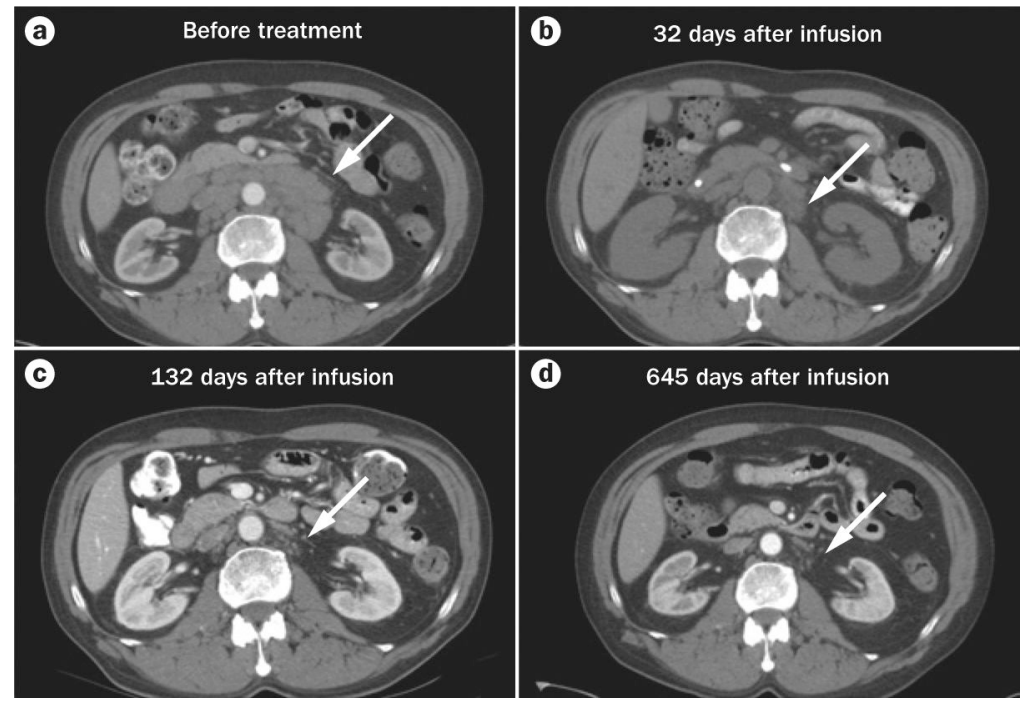

Figure $4 \mid$.

Regression of adenopathy occurred in a patient with CLL after treatment with chemotherapy followed by an infusion of anti-CD19 CAR T cells and IL-2. The arrow indicates the adenopathy. The CT scans are of patient 7 in Table 1: a | Before treatment, $\mathbf{b} \mid 32$ days after the anti-CD19 CAR T cell infusion, $\mathbf{c} \mid 132$ days after infusion, and $\mathbf{d} \mid 645$ days after infusion. Abbreviations: CAR, chimeric antigen receptor; IL, interleukin. Parts a, b and c reproduced with permission from American Society of Hematology @ Blood 119, 27092720 (2012). 


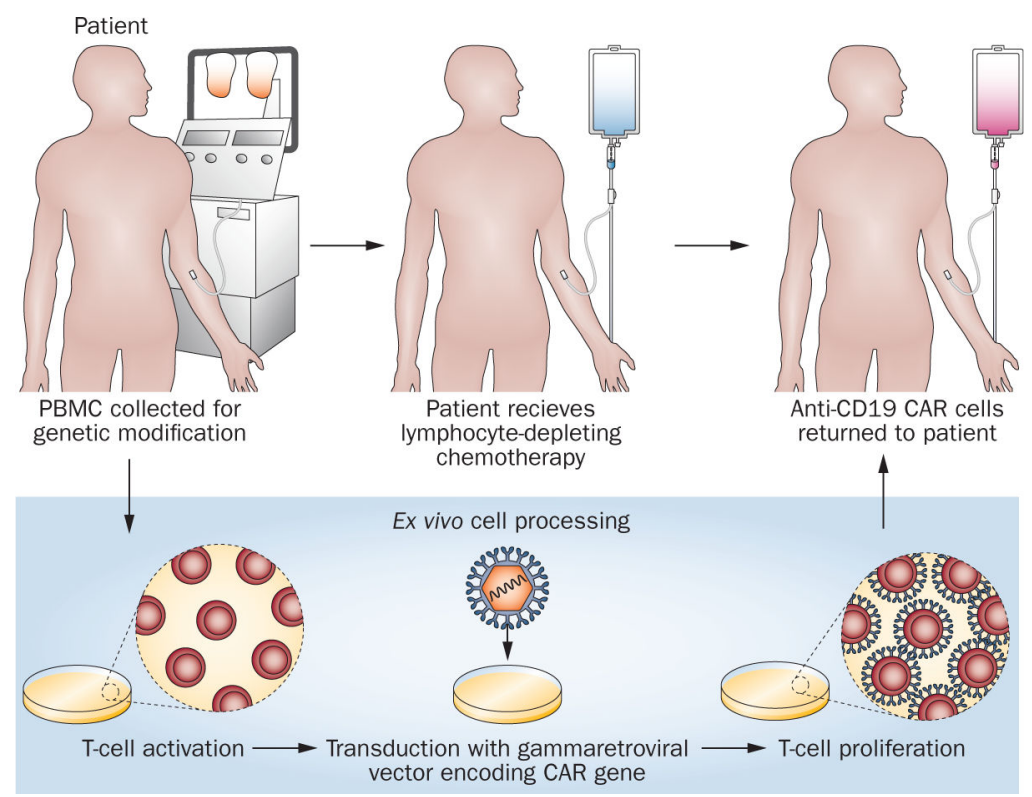

Figure $5 \mid$.

A schematic of our current approach to anti-CD19 CAR T cell therapy is shown. The $e x$ vivo cell processing takes 10 days. The lymphocyte-depleting chemotherapy regimen consists of fludarabine and cyclophosphamide. All patients receive $25 \mathrm{mg} / \mathrm{m}^{2}$ of fludarabine daily for 5 days. The cyclophosphamide dose depends on the patient's platelet count. A cyclophosphamide dose of $60 \mathrm{mg} / \mathrm{kg}$ daily for 2 days is administered to patients with a blood platelet count of $100,000 / \mu 1$ or more. A cyclophosphamide dose of $30 \mathrm{mg} / \mathrm{kg}$ daily for 2 days is administered to patients with a blood platelet count between 75,000 and 99,000/ $\mu$ l. Patients with platelet counts less than $75,000 / \mu \mathrm{L}$ are not eligible for the clinical trial. Abbreviations: CAR, chimeric antigen receptor; PBMC, peripheral blood mononuclear cell. 


$$
\text { 橧 }
$$




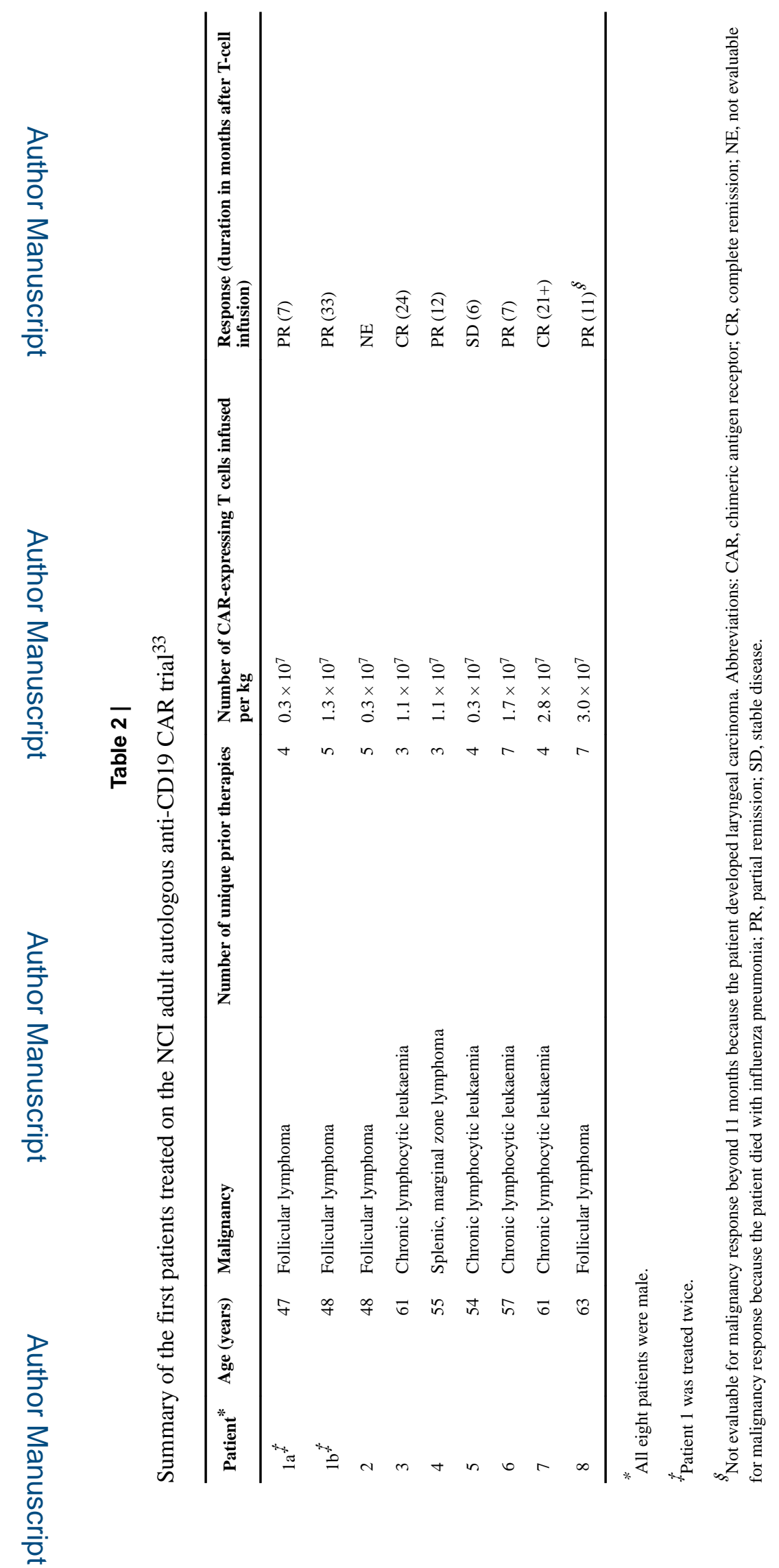

Nat Rev Clin Oncol. Author manuscript; available in PMC 2019 January 07. 


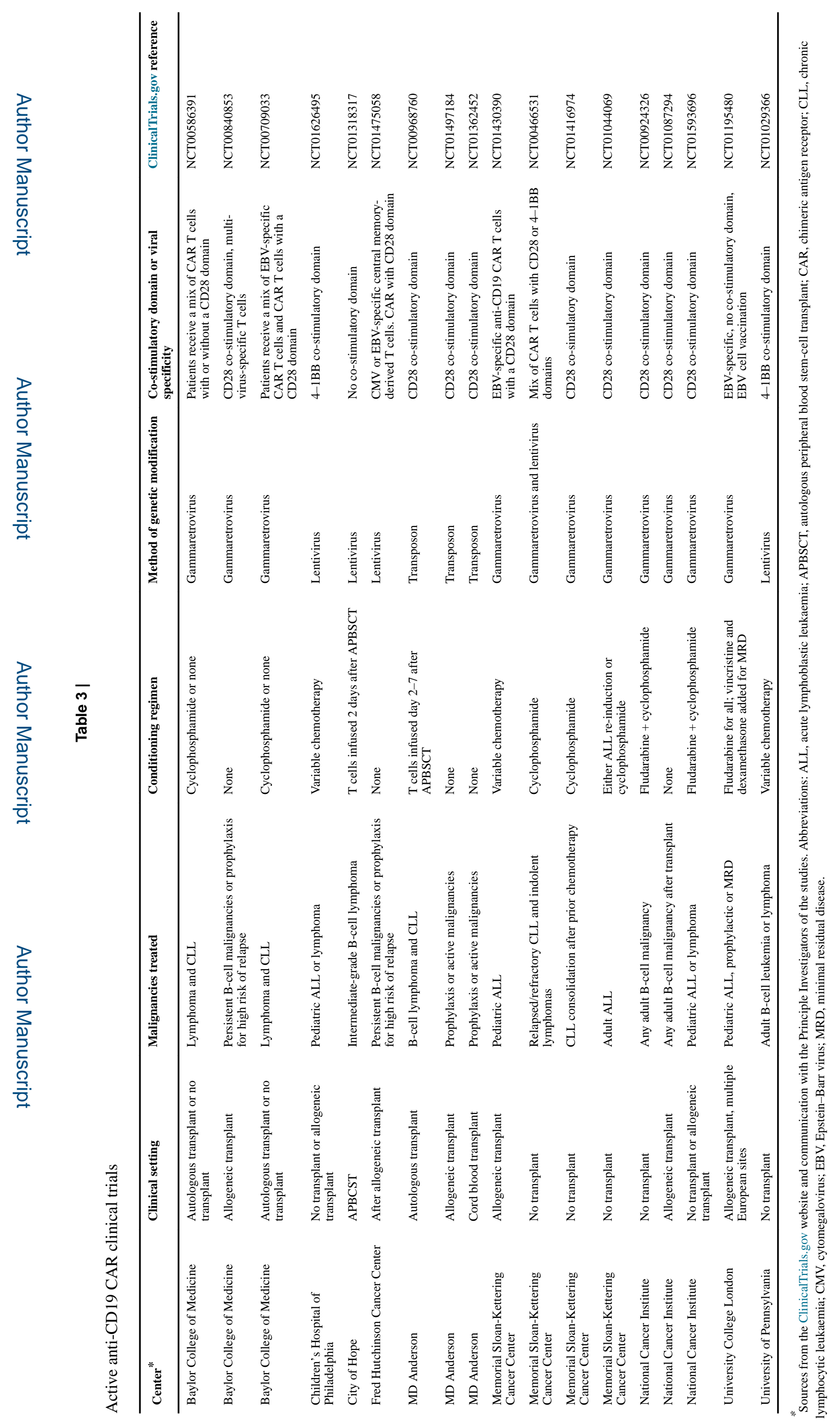

